\title{
INTERPRETACIÓN DEL PATRIMONIO Y GESTIÓN SOSTENIBLE DEL TURISMO EN ESPACIOS RURALES. LOS CASOS DE MONTEJO DE LA SIERRA Y PATONES ${ }^{1}$
}

\author{
Iris Martín Hernanz \\ Universidad Internacional de la Rioja \\ irs20@hotmail.com \\ Fernando Martín Gil \\ Departamento de Geografía. Universidad Autónoma de Madrid \\ f.martin@uam.es
}

\section{RESUMEN}

La Interpretación del Patrimonio es una herramienta de gestión disponible para la conservación del patrimonio natural y cultural. En las próximas páginas se aborda una revisión teórica sobre la materia, centrando la atención en sus potencialidades como instrumento de sostenibilidad turística en áreas rurales, y se evalúa su eficacia en dos casos de estudio en los que ha sido aplicada. El objetivo central de este trabajo es contribuir al mayor conocimiento de la disciplina en España y proponer ideas que fomenten su aplicación en la gestión sostenible del turismo en áreas rurales.

Palabras clave: Interpretación del Patrimonio, turismo rural, sostenibilidad turística, gestión del turismo, Patones, Montejo de la Sierra, conservación del patrimonio, puesta en valor del patrimonio.

Fecha de recepción: noviembre 2014.

Fecha de aceptación: septiembre 2015.

1 Este artículo incluye parte de las conclusiones de la Tesis Doctoral «La Interpretación del Patrimonio como herramienta de sostenibilidad turística en áreas rurales» defendida por la autora, dirigida por el coautor y defendida en 2012 en el Departamento de Geografía de la Universidad Autónoma de Madrid. 


\section{ABSTRACT}

Heritage Interpretation is a management tool available for cultural and natural heritage conservation. This theoretical revision about the topic focuses in its potentialities as a means of sustainable tourism in rural areas, and its efficiency is evaluated in two cases studies where it has been applied. The central aim of this research is to contribute to the knowledge on the discipline in Spain and to propose ideas that encourage its application in the sustainable tourism management of rural areas.

Keywords: Heritage Interpretation, rural tourism, sustainable tourism, tourism management, Patones, Montejo de la Sierra, heritage conservation, enhancement of heritage.

\section{INTRODUCCIÓN}

En la actualidad proliferan experiencias de desarrollo en áreas rurales que consideran al turismo como un sector central de revitalización socioeconómica. Teniendo en cuenta el valor estratégico de las funciones ambientales de estos territorios y los problemas socioeconómicos y culturales que atraviesan, parece necesario que su desarrollo se produzca bajo principios de sostenibilidad que garanticen la pervivencia de su patrimonio natural y cultural. El turismo rural en España ha crecido con intensidad en las tres últimas décadas. Incentivado por los nuevos valores y necesidades de las sociedades urbanas y por políticas públicas centradas en la búsqueda de alternativas económicas a las actividades agrarias, el fenómeno se ha extendido rápidamente a la práctica totalidad de las comarcas rurales españolas. Sin embargo, pese a su amplia difusión territorial y al crecimiento de la oferta de alojamiento, restauración y servicios complementarios, todavía queda un amplio camino por recorrer para que pueda considerarse una actividad sostenible. Entre las principales cuestiones a resolver destacan la creación de verdaderos destinos turísticos, de servicios de elevado valor añadido y productos diferenciados, la mejora de la calidad y la potenciación de su contribución al desarrollo endógeno. Esta última cuestión incluye la recuperación, conservación y puesta en valor del patrimonio territorial con propuestas que garanticen el equilibrio ambiental.

Disponemos de diferentes instrumentos para fomentar procesos sostenibles de desarrollo turístico. Algunos se dirigen a visitantes, empresas y destinos, como los códigos de buenas prácticas, las ecoetiquetas (Fullana y Ayuso, 2002), los centrados en reducir la huella ecológica de la actividad (Hunter y Shaw, 2007) o la zonificación de espacios naturales protegidos (Wearing y Neil., 1999). Otros, como la planificación estratégica, son de carácter integral y pueden diseñarse y aplicarse a diferentes escalas territoriales. Considerando sus objetivos, métodos y potencialidades para la puesta en valor, difusión y gestión del patrimonio, la Interpretación del Patrimonio (IP) puede ser un instrumento eficaz para el desarrollo sostenible del turismo. Además, puede ejercer un papel relevante en la conservación del patrimonio porque, bien diseñada y ejecutada, incide directamente en aspectos esenciales como la sensibilización de los visitantes y el fomento de actitudes de respecto en población local y turistas (Álvarez, 1999; Castells, 2002; Cebrian, 2001; Santamarina, 2008). Entre los principales objetivos de la IP destacan la conservación y protección del legado natural y cultural y para 
alcanzarlos fomenta su comprensión, sensibiliza, persuade y provoca a los visitantes para infundirles actitudes de respeto. Aunque se dirige a los visitantes también incide en la población local favoreciendo la conservación del patrimonio mediante el cambio de sus valores. En consecuencia, por depender de cambios en los valores de individuos y sociedades, sus beneficios se producen a medio y largo plazo.

Eagles et al. (2002) y Ham (1992) han constatado el papel de la IP en la gestión del uso de los visitantes de lugares de valor patrimonial mientras que otros autores postulan su capacidad potencial para reducir impactos de visitantes en áreas protegidas (Muñoz y Benayas, 2008). Entre los beneficios que genera destacan la erradicación de comportamientos indeseables de visitantes en espacios protegidos norteamericanos como alimentar osos negros (Parque Nacional Yosemite) y ardillas (Parque Estatal de Cráter) o evitar el robo de madera petrificada (Parque Nacional Bosque Petrificado) (Khol, 2009). Otros tienen relación con sus posibilidades para la sostenibilidad del turismo y la conservación del patrimonio y se manifiestan en experiencias como «Expediciones Liblad», que recaudó dos millones de dólares para el Fondo de Conservación de las Islas Galápagos mediante donativos de visitantes que utilizaban los servicios interpretativos, y la de «Fermata Inc» y la Universidad de Iohao con el programa de capacitación en interpretación que mostró su contribución en la reducción de especies invasoras del «Parque Bentsen Río Grande» (Khol, op. cit.).

En España la IP es una disciplina muy joven, al contrario de lo que sucede en los países anglosajones desarrollados donde las investigaciones realizadas han generado un considerable corpus teórico en la materia, evaluado su aplicación y aportado conocimientos aplicables al objetivo de conservación del patrimonio. En cualquier caso, existen importantes carencias a escala internacional porque pese al creciente protagonismo de la IP escasean investigaciones empíricas que evalúen su eficacia (Orams, 1996). Este déficit es mayor en el medio rural, especialmente en el caso español, por lo que apenas conocemos la incidencia de la disciplina en el correcto desarrollo del turismo en estos territorios, si bien es posible encontrar ejemplos en espacios naturales protegidos como Sierra Nevada, Tablas de Daimiel e Islas Atlánticas (Muñoz, 2008) y en áreas rurales burgalesas, como la Senda de la Naturaleza de Fuentes Blancas (Cebrian, op.cit.), que confirman sus posibilidades.

\section{LA CONTRIBUCIÓN DE LA INTERPRETACIÓN DEL PATRIMONIO A LA SOSTENIBILIDAD TURÍSTICA}

En sus inicios, la IP abordó de manera diferencial el patrimonio cultural y el natural y conforme evolucionó fue generando una visión global de los problemas que incluyó la perspectiva territorial. El origen histórico de la IP está ligado a los parques nacionales norteamericanos, cuando surge como respuesta a necesidades derivadas de la labor de acompañamiento de guías de naturaleza de espacios naturales protegidos a visitantes con diferentes perfiles y comportamientos (Morales, 1998); en este contexto, la exigencia de conjugar conservación y funciones recreativas fue abordada en parte con la IP conforme los guardas forestales tuvieron que convertirse en guías improvisados que orientaban a los visitantes. En Europa, la IP surgió ligada al patrimonio cultural en los Parques de la Vida Costumbrista escandinavos (Albridge, 1989). En concreto, en el Museo Nordista de Estocolmo. Esta génesis diferente 
se debe a circunstancias históricas, en tanto las transformaciones sociales, económicas y políticas derivadas de la revolución industrial han afectado más al medio natural de América y a los espacios humanizados en Europa, cuestión que explicaría la preferente atención al patrimonio cultural en éste último caso frente al interés específico por el patrimonio natural en Estados Unidos (Ortega, 1998). Sea como fuere, la IP surgió ligada a la planificación y la gestión, fundamentalmente de espacios naturales protegidos, al considerarse una herramienta eficiente para la conservación del patrimonio (Santamarina, 2008). Ahora bien, a esta función inicial se suman hoy otras derivadas de su capacidad para proporcionar diferentes lecturas y oportunidades para su aprovechamiento (Monteserín, 2006) que incluyen su transformación en producto cultural o turístico.

La IP es un proceso de comunicación que busca, mediante la revelación y la persuasión, la conservación del elemento o lugar patrimonial (Morales y Ham, 2008). Para lograrlo procura que el visitante se relacione con el patrimonio y el lugar y tenga experiencias relevantes y significativas que fomenten actitudes de custodia y respeto (Morales, Guerra y Serantes, 2009). Una de sus particularidades es el peso que concede al destinatario. Por definición, este es el público general entendido como visitante casual, no motivado, no cautivo y con un tiempo limitado. Para la IP la actitud o el estado mental de la audiencia es un aspecto central de interés, cuestión que la diferencian de las otras formas de comunicación (Ham, 2007). Además, la IP se dirige a grupos heterogéneos que se encuentran en su tiempo de ocio y cuya expectativa es meramente espiritual o estética. Considerando las características del destinatario la IP debe trasmitir información interesante, entretenida, comprensible y fácil de procesar, atributos necesarios para poder mantener la atención del público y conseguir sus objetivos. En este sentido Ham (1992) propuso el marco AROT sosteniendo que un mensaje debe ser ameno, relevante, organizado y temático. Otros investigadores añaden que un mensaje interpretativo debe poseer tres características principales: significancia, relevancia al ego y organización conceptual (Guerra, 2009).

Para facilitar que los visitantes formen sus propias conexiones con el significado del patrimonio se requiere un mensaje adecuado y el uso de técnicas interpretativas que impulsen la creación de vínculos intelectuales y emocionales (EUROPARC España, 2005). Entre las más utilizadas destacan el humor, la provocación, la imaginación, la ironía, el misterio, las comparaciones y analogías, los cuentos, los refranes, las demostraciones y las citas célebres. Aquellas que favorecen la participación de los visitantes, como el uso de los sentidos, los juegos de preguntas y respuestas, los debates, el desarrollo de actividades prácticas, la dramatización y la teatralización son muy eficaces porque propician la participación y generan actitudes proactivas, por su carácter seductor y embaucador y por tratarse de técnicas accesibles y entendibles por todo tipo de visitantes. Ahora bien, tan importantes como la elección de las técnicas son los medios para ejecutar el programa interpretativo (Spanle, et al, 1974) incluyendo el material utilizado como soporte para transmitir el mensaje (EUROPARC, op. cit.). En la selección del medio interpretativo, cuestión fundamental a la hora de diseñar y ejecutar un programa de calidad, debe considerar variables como su coste, facilidad de uso y mantenimiento, capacidad de carga del patrimonio, estética, patrones de uso, necesidades, características y preferencias del público (Guerra, 2009). Además, resulta fundamental considerar algunos criterios básicos para su evaluación. 
Desde el origen de la disciplina se han realizado múltiples esfuerzos orientados a establecer los criterios que deben manejarse a la hora de diseñar los programas o actividades de IP. Tilden (1957) fue uno de los pioneros en identificar una serie de principios básicos que, a la postre, son de gran utilidad para los profesionales de la disciplina:

- La IP debe relacionar el patrimonio que se presenta y describe con la experiencia del visitante.

- La información como tal no es interpretación, pero toda la interpretación incluye información.

- La interpretación es un arte, y una buena estrategia para ponerla en práctica es contar una historia ya que los visitantes buscan entretenimiento.

- La interpretación persigue provocar sentimientos, no tanto instrucción.

- Hay que presentar el todo y no las partes de forma aislada.

- La interpretación para niños requiere programas específicos

La IP puede utilizarse desde numerosas disciplinas y con fines diversos y su adecuada implantación asegura un mejor y más eficiente uso del patrimonio porque revela los significados que representa, conciencia sobre su valor, ofrece experiencias valiosas a los visitantes y cumple una misión de gestión para la institución que lo administra (Morales et al., op. cit.). Sus posibles beneficios se extienden más allá del ámbito ambiental generando múltiples impactos socioculturales y económicos positivos. Entre las principales potencialidades de la IP para la sostenibilidad destaca su contribución a la conservación del elemento o conjunto patrimonial y el territorio donde se emplaza en tanto modifica los comportamientos nocivos de los visitantes (Khol, 2009). Además, puede reducir los impactos del uso cultural y turístico del patrimonio mejorando su estado (Ham, 1992; Eargles et al, 2000), facilitando la gestión del flujo de visitantes, evitando la exposición de elementos o conjuntos patrimoniales y limitando el acceso independiente de visitantes. De manera indirecta contribuye a la conservación dando a conocer a los usuarios las políticas de gestión del patrimonio (Morales. el al., op. cit.), ayuda a incrementar la satisfacción de los visitantes ofreciendo experiencias valiosas y mayores oportunidades para el disfrute (Ham, 1992; Morales 1998; Eagles et al, 2002). En el ámbito sociocultural favorece la generación de sentimientos de orgullo, pertenencia e identidad entre la población local que propician la conservación de la autenticidad. Entre los impactos positivos de la IP en el mercado de trabajo y las economías locales destacan el fomento de la creación de nuevos nichos y oportunidades de empleo, en buena medida cualificado y desempeñado por jóvenes con elevada formación, y su contribución a mitigar la emigración juvenil y de capital humano, problema central de espacios con problemas económicos estructurales como las áreas rurales españolas. También ayuda a establecer y mantener el equilibrio entre beneficio económico y niveles de visitas deseables por los residentes, fomenta actitudes emprendedoras en las comunidades locales, aporta diferentes enfoques a la lectura del patrimonio útiles para su aprovechamiento (Monteserín, 2006), genera actividades económicas de elevado valor añadido, fomenta la especialización y tematización de destinos y productos y es un instrumento eficaz de comunicación, comercialización y promoción territorial (Castaño, 2005), cuestiones esenciales para un turismo sostenible. 
Considerando sus múltiples potencialidades (figura 1), la IP se postula como herramienta de interés para quienes trabajan en planificación y gestión del turismo desde una perspectiva de desarrollo equilibrado, especialmente en áreas rurales donde la actividad se plantea como vector fundamental de actuación. Pese a ello, en España abundan ejemplos donde su aplicación apenas genera impactos en el desarrollo desde principios de sostenibilidad. En numerosos casos esta situación deriva de un diseño inadecuado; en otros, de su uso como mero instrumento para la puesta en valor del patrimonio. A continuación abordaremos la cuestión mediante dos estudios de caso realizados en municipios rurales de la Comunidad Autónoma de Madrid (CAM).

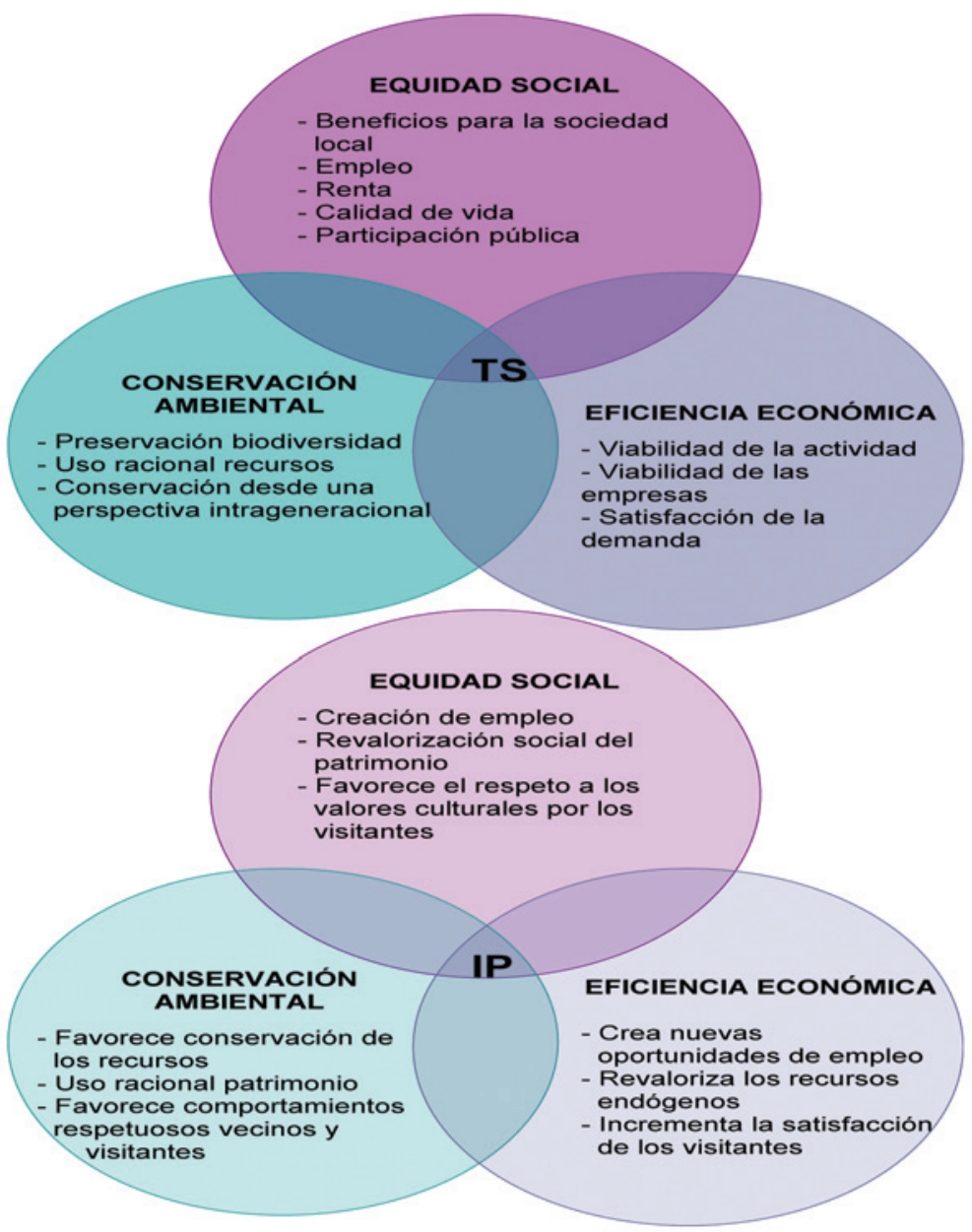

Fuente: elaboración propia. 


\section{EL TURISMO EN MONTEJO DE LA SIERRA Y PATONES: ACTIVIDAD ECONÓMICA CENTRAL CON PROBLEMAS DE SOSTENIBILIDAD}

Los estudios de caso se centran en el Hayedo de Montejo, espacio protegido de 250 has. declarado Sitio Natural de Interés Nacional (1974) e integrado en la Reserva de la Biosfera de la Sierra del Rincón, y el núcleo urbano de Patones de Arriba, declarado Bien de Interés Cultural en 1999. Ambos cuentan con patrimonio natural y cultural sometido a diversas fórmulas de protección, se localizan a escasa distancia de un gran centro emisor de turismo (Madrid), forman parte de los microdestinos de excursionismo de fin de semana más visitados por los madrileños, constituyen los principales focos de atracción turística de sus municipios y están sometidos a una intensa presión antrópica.

El Hayedo se localiza en Montejo de la Sierra, municipio serrano de $31,3 \mathrm{~km}^{2}$ de superficie y 300 habitantes, situado a $90 \mathrm{~km}$ de Madrid Capital y que cuenta con un patrimonio natural que incluye paisajes montañosos, masas forestales, la cabecera del río Jarama, una geológica propia de espacios serranos de transición y otros espacios naturales protegidos además del Hayedo. La mayoría de sus residentes son inactivos de edades avanzadas y los ocupados trabajan en actividades terciarias entre las que destaca el turismo. La principal singularidad ambiental del municipio es su Hayedo, ecosistema formado por uno de los bosque de hayas más meridionales de la Península. Este hecho constituye un poderoso factor de atracción turística para los madrileños, especialmente en otoño. Desde hace décadas los responsables del espacio y la administración local buscan soluciones para paliar problemas derivados de una excesiva afluencia de visitantes a este espacio frágil y para difundir los beneficios del turismo al conjunto del municipio. Entre las medidas aplicadas por los gestores del Hayedo destacan la restricción del número de visitantes, la creación de un sistema de visitas guiadas que incorporan la IP como herramienta de gestión del turismo y como servicio de turismo de naturaleza y la creación, en el entorno del Hayedo, de senderos autoguiados para visitantes que no pueden acceder al bosque. Por su parte, la administración local ha creado rutas alternativas para encauzar parte del flujo de visitantes al resto del municipio y difundir los beneficios económicos del turismo al conjunto de residentes.

El municipio de Patones $\left(34,5 \mathrm{~km}^{2}\right)$, localizado a escasa distancia de Montejo de la Sierra y a $65 \mathrm{Km}$. de Madrid, cuenta con dos núcleos de población de pequeñas dimensiones: Patones de Arriba, asentamiento primigenio y espacio donde se desarrolla el grueso de la actividad turística, y Patones de Abajo, lugar de residencia de sus aproximadamente quinientos habitantes. Como en Montejo, la mayoría de población es inactiva y el grueso de los ocupados trabaja en actividades terciarias, en este caso no turísticas. El núcleo de población original (Patones de Arriba) y su entorno cuenta con abundante patrimonio natural y cultural, aprovechado para el turismo, que incluye arquitectura vernácula, paisajes ganaderos y patrimonio arquitectónico agropecuario. Allí se concentran las infraestructuras turísticas, los principales recursos visitables, el grueso de la afluencia de visitantes y también los principales problemas derivados del turismo. El resto del municipio dispone de un amplio repertorio patrimonial, incluidos paisajes de montaña y una vega cultivada, apenas aprovechado para el turismo. En este escenario, Patones padece problemas que cuestionan la sostenibilidad de su desarrollo turístico como la saturación y con- 


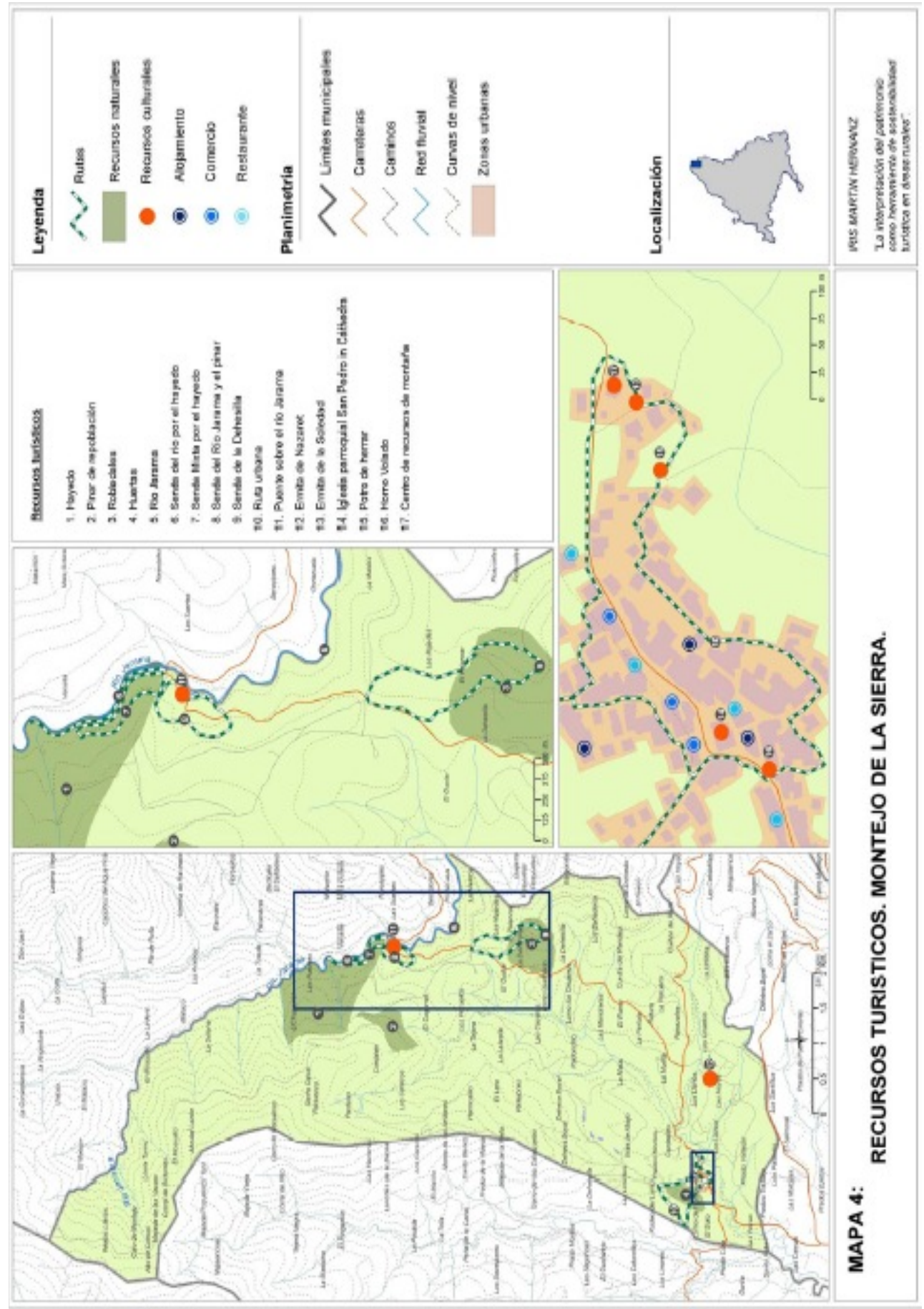




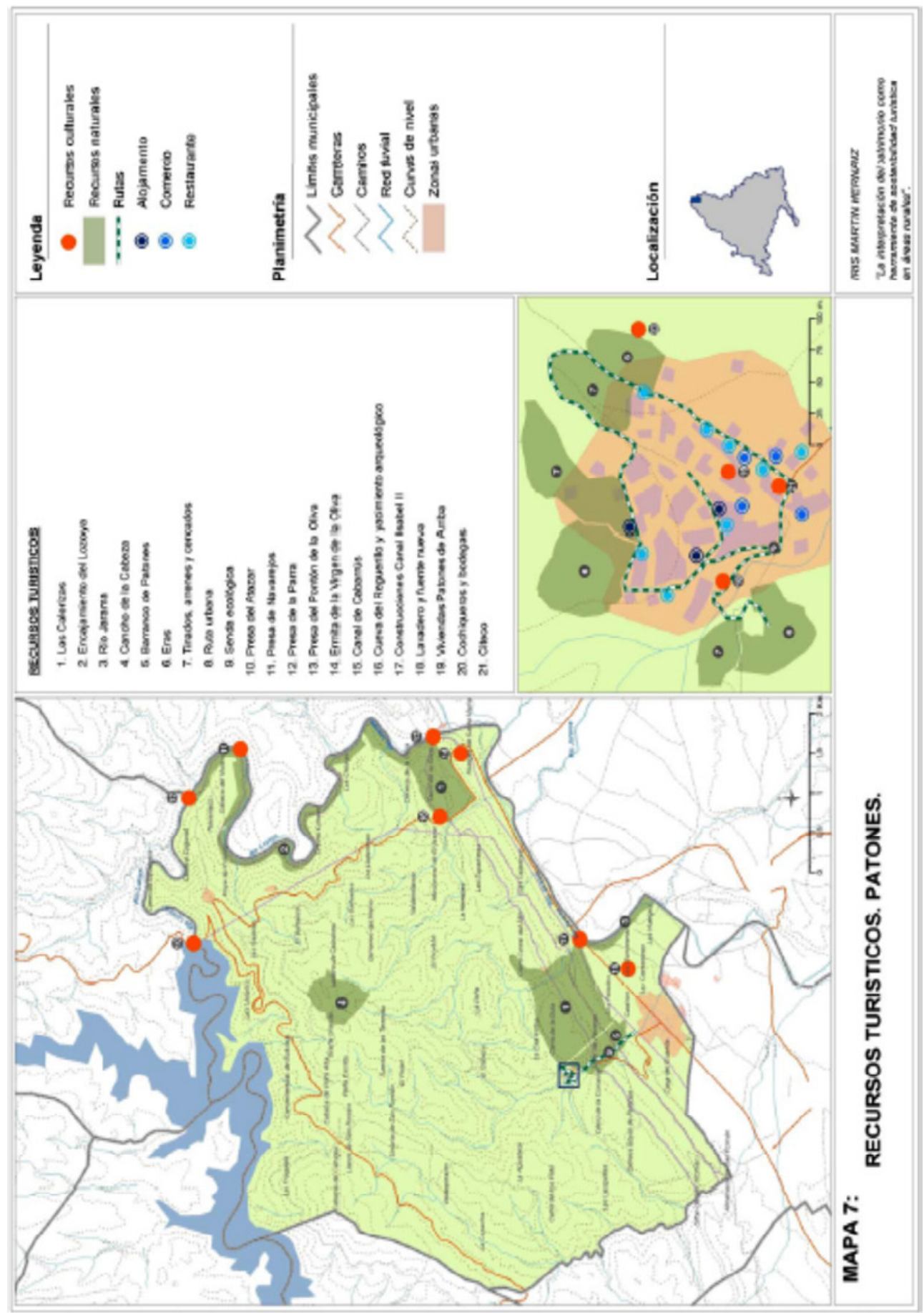


gestión de Patones de Arriba por afluencia masiva de excursionistas en fines de semana. Para minimizarlos se han aplicado diversas medidas que, en algún caso, incorporan la IP.

\section{METODOLOGÍA DE INVESTIGACIÓN}

La investigación, realizada entre 2007 y 2012, partió de dos hipótesis de trabajo: «la IP ha comenzado a utilizarse como herramienta de gestión turística en las áreas rurales españolas» y «la IP puede ser una herramienta eficiente para la sostenibilidad del turismo en las áreas rurales». Para corroborarlas se aplicó un plan de trabajo distribuido en tres fases y se diseñaron herramientas metodológicas específicas. En primer lugar se realizó un acercamiento documental al problema prestando especial atención a las propuestas de la Asociación Española para la Interpretación del Patrimonio (AIP). A continuación se identificaron experiencias en destinos turísticos rurales españoles con problemas de sostenibilidad turística que han aplicado propuestas de actuación que incluyen la IP. La tercera fase se centró en la realización de trabajo de campo orientado a recoger información, cualitativa y cuantitativa, necesaria para evaluar la situación del turismo en los territorios de referencia, identificar y analizar los problemas ambientales y socieoconómicos generados por la actividad, conocer la percepción de los actores involucrados sobre los problemas detectados, identificar y valorar las medidas correctoras aplicadas y la incidencia de aquellas que incluían IP (figura 2).

Figura 2

HERRAMIENTAS METODOLÓGICAS APLICADAS EN LOS ESTUDIOS DE CASO

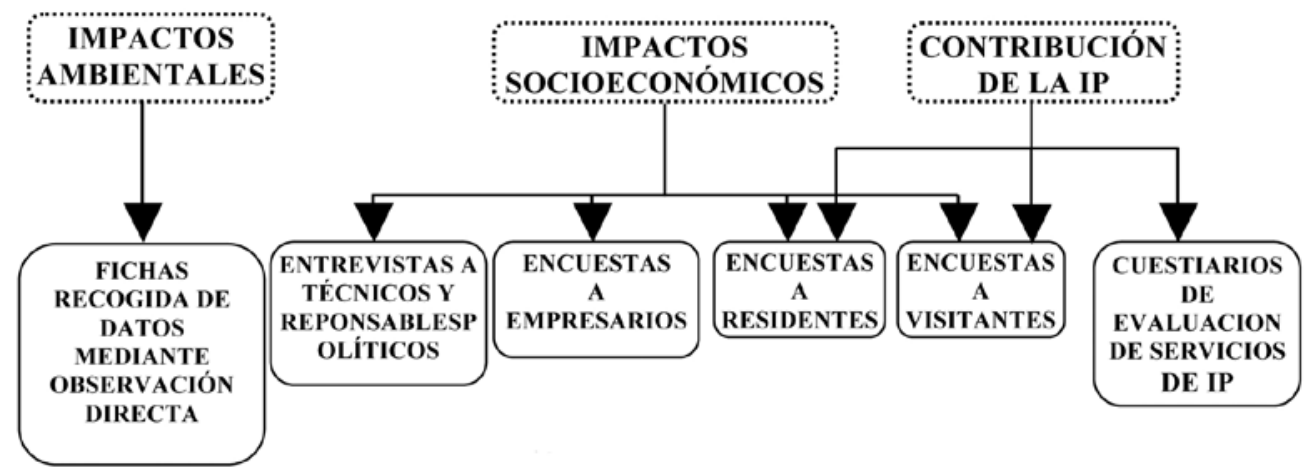

Fuente: elaboración propia.

Para evaluar la situación del turismo se procedió al análisis estadístico de variables significativas, se utilizaron resultados de estudios técnicos previos y se recopiló y analizó información cuantitativa y cualitativa mediante encuestas y entrevistas semiestructuradas dirigidas a un amplio perfil de agentes. La valoración de los impactos ambientales generados por los visitantes se abordó mediante observación directa. Para ello se diseñaron fichas específicas y se seleccionaron como lugares de recogida de información espacios muy frecuentados por visitantes donde se detectaron impactos derivados de la superación de la capa- 
cidad de carga o la práctica de actividades insostenibles. Con el objetivo de reducir sesgos asociados a la estacionalidad del flujo de visitantes se realizaron cinco salidas de trabajo, en cada estudio de caso, distribuidas en las cuatro estaciones del año. Los impactos ambientales fueron registrados y analizados a partir de una técnica de uso frecuente en Evaluación de Impactos Ambientales: la matriz de relaciones causa-efecto.

Para el análisis de percepciones y opiniones de actores involucrados en el desarrollo y gestión del turismo se realizaron encuestas y entrevistas semiestructuradas a técnicos de la administración, representantes políticos, empresarios, residentes y visitantes. El objetivo de la elección de este amplio espectro de agentes fue identificar y evaluar los principales problemas desde múltiples perspectivas que incluyen a implicados en la gestión del turismo y del patrimonio, usuarios, empresarios y afectados por la actividad turística. En total se realizaron ciento treinta encuestas y ocho entrevistas. Por último, para valorar las medidas correctoras aplicadas, la utilización de la IP y su contribución a la gestión y la planificación de un desarrollo turístico sostenible, se analizaron y evaluaron los equipamientos y servicios relacionados con la disciplina prestando especial atención a la calidad de los mismos. Tomando como hipótesis de partida la idea de que con frecuencia estos se definen como tales cuando en realidad no lo son, se diseñaron cuestionarios específicos para su evaluación. La información recopilada permitió valorar, entre otras cuestiones, los atributos que definen la calidad de la interpretación, mediante una escala del 1 al 4, en los dos centros de visitantes existentes, cuatro rutas autoguiadas y tres rutas guiadas. El modelo diseñado adaptó la metodología planteada para evaluar la calidad de visitas guiadas del Parque Nacional de Cabañeros (Benayas et al., 2000) y la calidad del uso público en la Red Española de Parques Nacionales (Benayas et al., 2007; Muñoz, 2008). Para validar el método y sus resultados se contó con la colaboración de un panel de expertos de la Asociación para la Interpretación del Patrimonio que revisó el sistema de evaluación y aportó propuestas de mejora. En total se aplicaron cincuenta y un indicadores agrupados en seis factores: gestión, diseño del equipamiento, diseño del medio y grupo, técnicas de IP aplicadas, mensaje y valoración general de los mismos (Tabla 1).

Tabla 1

INDICADORES DE EVALUACIÓN DE INTERPRETACIÓN DEL PATRIMONIO

\begin{tabular}{|l|l|l|l|}
\hline \multirow{5}{*}{ Centro Visitantes } & \multicolumn{1}{|c|}{ Ruta guiada } & \multicolumn{1}{c|}{ Ruta autoguiada } \\
\cline { 2 - 4 } & Información previa & Información previa & Información previa \\
\cline { 2 - 4 } Atención al público & Horarios & Señalización \\
\cline { 2 - 5 } & Cobro de servicios & Posibilidad reserva & Medios de apoyo \\
\cline { 2 - 5 } & Mantenimiento & Lugar recogida & $\begin{array}{l}\text { Satisfacción de } \\
\text { necesidades }\end{array}$ \\
\cline { 2 - 5 } & $\begin{array}{l}\text { Multifuncionalidad } \\
\text { gestión }\end{array}$ & - & $\begin{array}{l}\text { Grado de } \\
\text { mantenimiento }\end{array}$ \\
\cline { 2 - 5 } & $\mathrm{N}^{\text {tobajadores }}$ & - & - \\
\cline { 2 - 5 } & Formación & - & - \\
\cline { 2 - 5 } & Responsabilidad & - & - \\
\cline { 2 - 5 } & Trato al visitante & - & - \\
\hline
\end{tabular}




\begin{tabular}{|c|c|c|c|}
\hline \multirow{6}{*}{ DISEÑO } & Localización & Punto partida/llegada & P. partida/llegada \\
\hline & Construcción & Dureza recorrido & Dureza recorrido \\
\hline & Adecuación tamaño & Trazado & Trazado \\
\hline & Multifuncionalidad & Sentido circulación & Sentido circulación \\
\hline & $\begin{array}{l}\text { Satisfacción } \\
\text { necesidades }\end{array}$ & Paradas & Paradas \\
\hline & Accesibilidad & Accesibilidad & Accesibilidad \\
\hline \multirow{4}{*}{$\begin{array}{l}\text { DISEÑO DEL } \\
\text { MEDIO O } \\
\text { MATERIALES Y } \\
\text { GRUPO }\end{array}$} & Atractivo & Adecuado cc física & Atractivo \\
\hline & Adecuado & $\begin{array}{l}\text { Adecuado cc } \\
\text { perceptual }\end{array}$ & Adecuado \\
\hline & $\begin{array}{l}\text { Facilidad de } \\
\text { mantenimiento }\end{array}$ & Adecuado calidad IP & Fácil de mantener \\
\hline & Accesibilidad medio & - & Accesibilidad medio \\
\hline \multirow{5}{*}{$\begin{array}{l}\text { TÉCNICAS Y } \\
\text { RECURSOS }\end{array}$} & - & Comunicación guía & - \\
\hline & Humor, anécdotas... & Humor, anécdotas & Humor, provocación \\
\hline & Material de apoyo & Material de apoyo & Material de apoyo \\
\hline & $\begin{array}{l}\text { Participación / } \\
\text { implicación }\end{array}$ & $\begin{array}{l}\text { Participación / } \\
\text { implicación }\end{array}$ & $\begin{array}{l}\text { Participación / } \\
\text { implicación }\end{array}$ \\
\hline & - & Componente lúdico & - \\
\hline \multirow{8}{*}{$\begin{array}{l}\text { MENSAJE O } \\
\text { CONTENIDOS }\end{array}$} & Tema central & Tema central & Tema central \\
\hline & Cantidad información & Cantidad info. & Cantidad info. \\
\hline & $\begin{array}{l}\text { Significativo / } \\
\text { adecuado }\end{array}$ & $\begin{array}{l}\text { Significativo / } \\
\text { adecuado }\end{array}$ & $\begin{array}{l}\text { Significativo / } \\
\text { adecuado }\end{array}$ \\
\hline & Relevante/pertinente & Relevante/pertinente & Relevante/pertinente \\
\hline & Conceptos intangibles & Conceptos intangibles & Conceptos intangibles \\
\hline & $\begin{array}{l}\text { Conexiones } \\
\text { intelectuales }\end{array}$ & $\begin{array}{l}\text { Conexiones } \\
\text { intelectuales }\end{array}$ & $\begin{array}{l}\text { Conexiones } \\
\text { intelectuales }\end{array}$ \\
\hline & Estimula pensamiento & Estimula pensamiento & Estimula pensamiento \\
\hline & Actitud de custodia & Actitud de custodia & Actitud de custodia \\
\hline \multirow{5}{*}{$\begin{array}{l}\text { VALORACIÓN } \\
\text { GENERAL }\end{array}$} & Atractivo & Atractivo & Atractivo \\
\hline & - & Conducción grupo & - \\
\hline & Refuerza tema & Refuerza tema & Refuerza tema \\
\hline & Satisfacción & Satisfacción & Satisfacción \\
\hline & Valoración general & Valoración general & Valoración general \\
\hline
\end{tabular}

Fuente: elaboración propia.

Los resultados obtenidos permitieron elaborar sendas evaluaciones en cada estudio de caso, realizar análisis comparados y aportar una visión global de los problemas que incluye aspectos centrales del uso de la IP como instrumento para la gestión sostenible del turismo en espacios rurales. 


\section{LOS PROBLEMAS DE SOSTENIBILIDAD DEL TURISMO EN EL HAYEDO DE MONTEJO Y PATONES DE ARRIBA. EVALUACIÓN DE LA APLICACIÓN DE LA INTERPRETACIÓN}

\section{V.1. Los orígenes de los problemas}

Montejo de la Sierra y Patones son microdestinos rurales maduros de la CAM en los que predomina el excursionismo sobre el turismo. El principal factor de atracción de Montejo es su pequeño hayedo y su consolidación como centro de atracción turística de la Sierra Norte de Madrid, el incremento del número de visitantes y los problemas derivados de una excesiva afluencia turística surgieron a partir de la declaración del bosque como Sitio Natural de Interés Nacional (1974) y la ejecución, en la década de los ochenta, de dos proyectos de desarrollo turístico (Programa Culturalcampo del $\mathrm{M}^{\mathrm{o}}$ de Cultura y Programa Especial de Rehabilitación de Edificios de la CAM). Los resultados de ambos proyectos, el fomento del turismo por las administraciones locales y regional, la repercusión de estrategias de promoción indiscriminadas y factores externos (conversión de la Carretera Nacional I en autovía e incremento de la práctica de actividades de ocio y turismo entre los madrileños) provocaron un rápido incremento de las visitas al Hayedo a finales de los años ochenta. Desde entonces comenzaron a producirse impactos ambientales que degradaban el ecosistema cuestionando su sostenibilidad. En este contexto la CAM, en colaboración con la administración local, restringió el número de visitantes y reguló las visitas que, hasta la actualidad, requieren autorización previa y acompañamiento de guía especializado. A mediados de los noventa del siglo XX Montejo ofrecía, además de recorridos por el Hayedo, un Centro de Visitantes, seis alojamientos rurales, un camping, tres restaurantes, un hostal y un centro de servicios polivalentes con alojamientos (González, 1995). La declaración de la Sierra del Rincón como Reserva de la Biosfera (2005) fue el último hito de la evolución turística del municipio: fortaleció su imagen de destino de naturaleza y turismo rural e incorporó una nueva institución competente en materia de conservación ambiental, desarrollo y turismo. Siete años después, en 2012, la oferta de alojamiento había aumentado a siete establecimientos y su grado de ocupación superaba a la media comarcal (Centro de Innovación Villa San Roque, 2008). Montejo contaba, además, con cinco restaurantes, senderos acondicionados para la práctica turística, áreas recreativas, rutas guiadas y diversos comercios además de un Centro de Visitantes. El número anual de visitantes se estima en torno a 25.000 entre los que predominan parejas o familias con poder adquisitivo medio y elevado nivel de estudios. En su mayoría proceden de Madrid, acuden en vehículo privado, realizan visitas cortas, fundamentalmente en otoño, y sus principales motivaciones son conocer el Hayedo, realizar turismo de naturaleza y deportivo (Ruiz y Moreno, 2001, CAM, 2008).

La evolución turística de Patones, paralela en algunos aspectos a la de Montejo, tiene una génesis diferente. Entre las décadas de los años cincuenta y sesenta del siglo XX los vecinos de Patones de Arriba abandonaron el lugar para trasladarse al recién construido Patones de Abajo. Cuando Patones de Arriba había sido prácticamente abandonado, a finales de los 60 , comenzó a ser ocupado por nueva población compuesta por profesionales urbanos y jóvenes neorrurales que vivían en comunidad en viviendas arrendadas o compradas, a sus propietarios históricos, a bajos precios. En este contexto se abrió el primer negocio en los años 70. A mediados de los 80 un decorador francés compró un 
primer inmueble, lo rehabilitó y transformó en hotel. Este fue el detonante de lo que sería un intenso crecimiento del turismo. Entre tanto, desaparecieron los jóvenes neorrurales y en los inmuebles vacantes se inició un nuevo proceso de ocupación siendo adquiridos por emprendedores que los rehabilitaron y reconvirtieron en restaurantes. Al final del proceso apenas quedaban propietarios de viviendas oriundos de Patones y conforme se creaban expectativas de desarrollo turístico el precio del suelo aumentó. Por último, en los años 90 se produjo la eclosión del turismo en este pequeño núcleo de calles estrechas y desde entonces miles de personas llegan los fines de semana generando actividad económica y empleo a la vez que problemas de congestión y saturación. Mientras Montejo se especializaba en turismo de Naturaleza Patones se orientó al gastronómico. Fruto de ello son los trece restaurantes existentes en 2012 (11 en Patones de Arriba, 2 en Patones de Abajo) con un total de 750 plazas. En la misma fecha el municipio disponía de cinco alojamientos, un centro de visitantes con oficina de turismo y sala de exposiciones, un museo al aire libre, otro emplazado en un inmueble rehabilitado, senderos autoguiados, tiendas de regalos y artesanía, oferta que genera en torno a 80 puestos de trabajo ocupados, en su mayoría, por no residentes. El número de visitantes anuales de Patones de Arriba se sitúan en, al menos, veinticinco mil, a los que se suman los tres mil quinientos que llegan al Pontón de la Oliva, segundo lugar más visitado del municipio emplazado a tres kilómetros de distancia por carretera. El perfil básico del visitante es similar al de Montejo: predominan parejas y grupos de amigos con poder adquisitivo medio y elevado nivel de estudios, que proceden de Madrid, llegan en vehículo privado, realizan visitas cortas, fundamentalmente en otoño y primavera, muestran elevados grados de satisfacción con la oferta turística y de fidelidad al destino y sus motivaciones principales son conocer el pueblo, realizar actividades al aire libre y comer en algún restaurante (MERCODES, 2003).

El desarrollo turístico de Patones de Arriba se produjo en un corto periodo de tiempo provocando impactos positivos como la rehabilitación y conservación del patrimonio arquitectónico residencial y agropecuario, la creación de un número importante de empleos y nuevo tejido productivo. Pero su carácter espontáneo, crecimiento desordenado y excesiva concentración espacial de oferta y demanda generan congestión ambiental y saturación de infraestructuras, problemas a los que se suman una excesiva especialización en turismo gastronómico, un fuerte incremento del precio del suelo y la vivienda y un aplastante predominio de agentes foráneos en el tejido empresarial que genera tensiones con la población local. Aunque en Montejo de la Sierra el desarrollo turístico estuvo planificado en sus inicios, también se produjo en breve tiempo un rápido incremento de visitantes como resultado del impacto de estrategias de promoción indiscriminadas y el efecto llamada de la declaración de espacio protegido del Hayedo y de Reserva de la Biosfera de la comarca. Aunque en este caso la mayoría de los impactos negativos del turismo también derivan de la saturación cíclica de visitantes, a diferencia de Patones los impactos no se concentran en el núcleo de población sino en el Hayedo y sus proximidades. En Patones los problemas se manifestaron en breve plazo de tiempo pero la necesidad de buscar soluciones surgió cuando alcanzaron dimensiones de una envergadura que, a la postre, los haría difíciles de eliminar y/o minimizar. En Montejo, por el contrario, ante los primeros problemas de sostenibilidad se comenzaron a buscar y aplicar medidas. Sea como fuere, tanto en uno como en otro caso el turismo se ha consolidado como principal actividad económica local 
y un número excesivo de visitantes genera problemas de sostenibilidad que han tratado de solucionarse con diferentes medidas. Como planteamos más adelante, algunas incorporan la IP pero con desigual enfoque y eficacia.

\section{V.2. La perspectiva técnica y la percepción de los actores implicados}

Los principales impactos ambientales del turismo en Montejo y Patones se asocian al acceso y estacionamiento inadecuado de vehículos en el entorno de los principales recursos visitados y sus causas son comunes: un número excesivo de visitantes que llegan en vehículo privado, sobre todo en otoño, primavera y fines de semana y se concentran en espacios frágiles de reducidas dimensiones: Patones de Arriba y proximidades del Hayedo. Ahora bien, estos problemas afectan con desigual intensidad en uno u otro caso y son percibidos de forma diferente por los agentes locales, cuestión que dificulta su resolución.

En los últimos años apenas ha habido cambios significativos en el perfil, hábitos y comportamientos de los visitantes respecto a períodos previos. Sigue siendo mayoría (82\% en Montejo y $81,6 \%$ en Patones) la presencia de madrileños que viajan de manera independiente en vehículo privado y permanecen unas horas antes de regresar a sus lugares de residencia. La principal diferencia entre ambos casos se centra en el número y diversidad de actividades realizadas, superiores en Patones, destacando el mayor porcentaje de visitantes que comen en restaurantes $(53,3 \%$ frente al 40\%). Sin embargo, sí se aprecian notables diferencias en los problemas percibidos por los visitantes. En Montejo ocupa el primer lugar (21\%) el cierre de los aseos públicos, el segundo la insuficiente dotación y mantenimiento de contenedores y papeleras $(10,5 \%)$ y a continuación se sitúan la escasa señalización e información y el déficit de espacios para estacionamiento de vehículos (8\% en todos los casos). En Patones, el primer lugar se sitúa el estacionamiento (30\%), a continuación el acceso a Patones de Arriba (15\%), la escasez de información $(11,5 \%)$ y el exceso del número de vehículos estacionados en Patones de Arriba (7,5\%). En cualquier caso, considerando los elevados grados de fidelidad a los destinos (el 40\% de encuestados en Montejo y el 40,4\% de Patones habían visitado el municipio al menos una vez más) y de satisfacción con la visita (el 58\% de Montejo y el 49\% de Patones la consideran mejor de lo esperado) para buena parte del colectivo los problemas no tienen dimensiones suficientes para generar actitudes de rechazo ante posibles regresos.

Entre los residentes son amplia mayoría quienes perciben el turismo como actividad beneficiosa ( $80 \%$ en Montejo y $81,8 \%$ en Patones) pero un porcentaje relevante no se manifiesta en este sentido. Los principales motivos de insatisfacción en Montejo son las molestias derivadas del tráfico, el aparcamiento y el ruido porque alteran la tranquilidad de la vida cotidiana; en Patones se centran en la excesiva especialización en turismo gastronómico y en que el turismo sólo favorece a los empresarios. Esta última cuestión resulta especialmente relevante puesto que desde hace años pervive un sentimiento de malestar relacionado con la desigual distribución de los beneficios y de los problemas derivados del turismo: parte de los residentes consideran que son ellos quienes sufren los problemas y «otros», que no residen en el pueblo y tienen sus negocios en Patones de Arriba, quienes más se benefician y menos los padecen. La pérdida del control del suelo y la vivienda de Patones de Arriba, tras su venta a agentes externos cuando el turismo despuntaba, y la escasa presencia de residentes entre el empresariado ayudan a entender esta situación. 
La percepción de los empresarios locales difiere de la del resto de agentes y muestra claras divergencias entre Montejo y Patones. En Montejo los principales problemas percibidos son la excesiva estacionalidad de la demanda (60\%) y la escasa rentabilidad de la actividad (20,5\%). En Patones son la congestión del tráfico y el estacionamiento de vehículos (85\%) y se plantean posturas críticas con la labor de la administración local en la gestión del turismo. Por último, las percepciones del personal técnico y responsables políticos muestran similitudes en ambos casos y diferencias notables que también se extienden a las percibidas por el resto de actores. En Montejo los principales problemas son la estacionalidad de la afluencia turística, el escaso asociacionismo, la insuficiente promoción, la escasez de infraestructuras y la insuficiente capacidad de estacionamiento en el entorno del Hayedo y el núcleo urbano. Además se considera, en términos generales, que el modelo turístico del municipio es sostenible. En Patones los principales problemas percibidos son la saturación cíclica de visitantes, el tráfico de vehículos y su estacionamiento, la falta de coordinación entre empresarios y determinados comportamientos negativos de los de visitantes. En este caso, al contrario que en Montejo, los entrevistados consideran insostenible el modelo turístico.

Tabla 2

LOS TRES PRINCIPALES PROBLEMAS PERCIBIDOS POR LOS AGENTES LOCALES

\begin{tabular}{|c|c|c|c|}
\hline $\begin{array}{l}\text { Visitantes de } \\
\text { Montejo }\end{array}$ & $\begin{array}{l}\text { Cierre de aseos } \\
\text { públicos }\end{array}$ & $\begin{array}{l}\text { Señalización, } \\
\text { mantenimiento de } \\
\text { contenedores }\end{array}$ & $\begin{array}{l}\text { Información y } \\
\text { estacionamiento de } \\
\text { vehículos }\end{array}$ \\
\hline $\begin{array}{l}\text { Visitantes de } \\
\text { Patones }\end{array}$ & Estacionamiento & Acceso a P. de Arriba & $\begin{array}{l}\text { Información y exceso } \\
\text { vehículos estacionados } \\
\text { en Patones de Arriba }\end{array}$ \\
\hline $\begin{array}{l}\text { Residentes en } \\
\text { Montejo }\end{array}$ & $\begin{array}{l}\text { Tráfico y } \\
\text { estacionamiento }\end{array}$ & Ruido & \\
\hline $\begin{array}{l}\text { Residentes en } \\
\text { Patones }\end{array}$ & $\begin{array}{l}\text { Excesiva } \\
\text { especialización en } \\
\text { turismo gastronómico }\end{array}$ & $\begin{array}{l}\text { Desigual distribución } \\
\text { de beneficios del } \\
\text { turismo }\end{array}$ & \\
\hline $\begin{array}{l}\text { Empresarios de } \\
\text { Montejo }\end{array}$ & $\begin{array}{l}\text { Estacionalidad de la } \\
\text { demanda }\end{array}$ & $\begin{array}{l}\text { Escasa rentabilidad de } \\
\text { la actividad }\end{array}$ & \\
\hline $\begin{array}{l}\text { Empresarios de } \\
\text { Patones }\end{array}$ & Congestión del tráfico & $\begin{array}{l}\text { Estacionamiento de } \\
\text { vehículos }\end{array}$ & $\begin{array}{l}\text { Labor de la } \\
\text { administración local }\end{array}$ \\
\hline $\begin{array}{l}\text { Políticos y técnicos } \\
\text { de Montejo }\end{array}$ & $\begin{array}{l}\text { Estacionalidad de la } \\
\text { afluencia turística }\end{array}$ & $\begin{array}{l}\text { Escaso } \\
\text { asociacionismo }\end{array}$ & $\begin{array}{l}\text { Promoción insuficiente, } \\
\text { infradotación en } \\
\text { infraestructuras y } \\
\text { estacionamiento }\end{array}$ \\
\hline $\begin{array}{l}\text { Políticos y técnicos } \\
\text { de Patones }\end{array}$ & $\begin{array}{l}\text { Saturación cíclica de } \\
\text { visitantes }\end{array}$ & $\begin{array}{l}\text { Tráfico y } \\
\text { estacionamiento de } \\
\text { vehículos }\end{array}$ & $\begin{array}{l}\text { Descoordinación entre } \\
\text { agentes }\end{array}$ \\
\hline
\end{tabular}

Fuente: elaboración propia.

Los análisis realizados concluyen que los principales problemas percibidos por los agentes son, en los dos estudios de caso, la congestión periódica del tráfico y el estacionamiento de vehículos, a los que se unen, en un segundo nivel, los relacionados con la gestión del fenó- 
meno turístico (falta de tejido asociativo, descoordinación entre agentes, distribución de los beneficios...). Los resultados también evidencian diferencias en la percepción sobre la sostenibilidad del turismo en Montejo y Patones que se explican, en buena medida, en función del modelo de gestión del turismo y el emplazamiento de los atractivos con mayor capacidad de atracción. En Montejo, el elemento patrimonial más visitado es el Hayedo, un espacio protegido financiado y gestionado por la CAM, regido por una legislación sectorial (espacios naturales) restrictiva con los usos turísticos, con visitas reguladas y limitadas y emplazado a suficiente distancia del núcleo de población como para que los problemas de congestión y saturación del entorno no incidan en exceso en la vida cotidiana de los residentes. En Patones, el lugar más visitado es Patones de Arriba, núcleo gestionado por la administración local, afectado por otra legislación sectorial (patrimonio cultural) menos restrictiva con los usos turísticos, y principal foco de problemas que, por su cercanía a Patones de Abajo, afectan a la vida diaria de los residentes y condicionan negativamente el propio desarrollo de las actividades turísticas. Esta situación genera mayor preocupación entre los residentes, los representantes políticos locales, responsables únicos en la materia, y entre los técnicos entrevistados que trabajan en su mayoría para el Ayuntamiento. En cuanto a problemas extendidos en áreas rurales españolas y de otros países como el escaso asociacionismo, participación e implicación de empresarios y residentes en la gestión del desarrollo turístico y la descoordinación entre agentes (Saxena y Ilbery, 2007, Liu y Wall 2006), medidas recomendadas por organismos internacionales orientadas a fortalecer el liderazgo de las administraciones y su apoyo a las comunidades locales mediante información, infraestructuras y mantenimiento (Jackson y Murphy, 2006), ya se abordaron en el caso de Patones, con Mesas Sectoriales de participación y debate, aunque fracasaron. Para finalizar, en los problemas percibidos por los agentes destaca la ausencia de referencias a conflictos relacionados con la degradación del patrimonio visitado, un vacío relevante por tres motivos. El primero es que ningún colectivo plantea problemas al respecto. El segundo, que buena parte de los problemas percibidos derivan en procesos de degradación del patrimonio y el tercero, y más importante para el tema que nos ocupa, que tan notoria ausencia remite a considerar el fracaso de las medidas aplicadas que incorporaran IP porque ni siquiera han logrado sensibilizar a los agentes acerca de estas cuestiones.

\section{V.3. Medidas correctoras aplicadas}

En la búsqueda de soluciones al problema de conservación del patrimonio que plantea la masificación de visitas en el Hayedo y para reducir la congestión y saturación del entorno, una vez restringido el número máximo de visitantes/día en Montejo se abordaron una serie de actuaciones de manera integrada: acondicionamiento de una senda ecológica, organización de visitas guiadas por el hayedo, publicación de la monografía «La Sierra del Rincón: Hombre y Naturaleza a través del tiempo», diseño de un programa de Educación Ambiental y creación de los senderos y rutas autoguiadas en las proximidades del Hayedo ( «Senda de la dehesilla» y «Senda del río Jarama y el pinar»). Estas dos rutas incorporan IP, al igual que la visita guiada al Hayedo y el Programa de Educación Ambiental. Para minimizar los impactos generados por el tráfico y estacionamiento de vehículos en Patones se diseñaron varios proyectos, algunos ejecutados, como el cierre al tráfico de vehículos privados de Patones de 
Arriba, el acondicionamiento de la «Senda Ecológica del Barranco de Patones» y la creación de un «Estacionamiento en Patones de Abajo» y otros, como la creación de un «Servicio de transporte público colectivo para unir el estacionamiento de Patones de Abajo con Patones de Arriba», que no llegaron a término. De todos ellos sólo uno, «La Senda Ecológica», incorporó IP en paneles que jalonan su recorrido. Por último, con los objetivos de concienciar a visitantes y población local sobre la importancia del patrimonio territorial y su conservación y difundir el turismo a ámbitos municipales diferentes a Patones de Arriba se realizó el proyecto «Diseño de una guía interpretativa del patrimonio natural y cultural del municipio de Patones» y la publicación «Un paseo por Patones: itinerarios didácticos para la Interpretación del Patrimonio». Si bien estas son las únicas propuestas íntegramente elaboradas desde la perspectiva de la contribución de la IP a la gestión sostenible del turismo y la conservación del patrimonio, su incidencia ha sido mínima en tanto no se ha aplicado.

Para desestacionalizar el turismo y difundir sus beneficios más allá de los actuales focos de atracción (Hayedo y Patones de Arriba) se llevaron a cabo, en ambos casos, múltiples acciones que incorporan la IP. En Montejo los principales esfuerzos se volcaron en la puesta en valor de patrimonio municipal con el objetivo de ampliar y diversificar la oferta, atraer visitantes en períodos valle de afluencia, incrementar los beneficios del turismo y reducir la presión sobre el Hayedo. Entre otras actuaciones se crearon rutas y senderos en torno al Hayedo y otros ámbitos del municipio, dotadas con paneles de información direccional, ambiental y cultural. En Patones se creó el Centro de Visitantes (CITECO) con funciones de pequeño museo, centro de interpretación y oficina de información turística, y el «Ecomuseo de la Pizarra», emplazado al aire libre, que puso en valor patrimonio histórico y cultural de Patones de Arriba. Además se elaboraron proyectos que no llegaron a ejecutarse, como la visita al yacimiento arqueológico, localizado en el paraje de «La Oliva», y un museo de la ganadería que incluía la reconstrucción de una instalación de producción de queso artesanal. A diferencia de Montejo las actuaciones ejecutadas se localizan en su totalidad en Patones de Arriba, decisión que refuerza la concentración de oferta y la presión turística en este núcleo de población. Por el contrario, las actuaciones no ejecutadas (yacimiento arqueológico y museo de la ganadería), diseñadas para poner en valor nuevo patrimonio y reducir la presión del turismo en Patones de Arriba, se localizan lejos de este núcleo de población e incorporaban la IP. Por último, para fortalecer el asociacionismo y la coordinación entre agentes el Ayuntamiento de Patones organizó, en los primeros años del siglo actual, mesas de trabajo que tenían como objetivo el debate, discusión y negociación de la gestión del desarrollo turístico entre agentes económicos, población local y representantes públicos. Aunque todos fueron invitados a participar la experiencia fracasó. La reducida asistencia de residentes, la escasa colaboración y la desconfianza entre agentes junto a una limitada capacidad de liderazgo de la administración local explican este fracaso.

Independientemente de su grado de ejecución las medidas señaladas no tienen el mismo significado para el conjunto de agentes que operan en el turismo o son afectados por la actividad. Entre los visitantes las más valoradas se relacionan directamente con la resolución de los problemas que más les afectan, como la congestión del tráfico y el aparcamiento de vehículos. En Patones el primer lugar (valoración de 8 sobre 10) corresponde a la creación del sistema de transporte colectivo que nunca llegó a operar. La segunda, en este caso sí ejecutada, es la construcción de un aparcamiento en Patones de Abajo $(7,5)$ desde el que partiría 
el trasporte colectivo y una senda de 300 metros para acceder a Patones de Arriba, en este caso ejecutada y dotada infraestructuras de IP. Por su parte, en Montejo la medida más valorada por los visitantes vuelve a ser la creación de un sistema de transporte colectivo desde Montejo al Hayedo $(8,1)$. En ambos casos el establecimiento de una cuota diaria de vehículos son medidas muy poco valoradas (5,3 en Montejo y 4,8 en Patones de Arriba).

Tabla 3

VALORACIÓN DE LAS MEDIDAS POR LOS AGENTES LOCALES (ESCALA: 1 MÍNIMO Y 10 MÁXIMO)

\begin{tabular}{|l|c|c|c|c|c|c|}
\hline Medidas & \multicolumn{2}{|c|}{ Visitantes } & \multicolumn{2}{c|}{ Residentes } & \multicolumn{2}{c|}{ Empresarios } \\
\hline & Montejo & Patones & Montejo & Patones & Montejo & Patones \\
\hline Transporte colectivo & 8,1 & 8 & 6,9 & 8 & 8 & 5,7 \\
\hline $\begin{array}{l}\text { Restricción tráfico/cuota } \\
\text { diaria vehículos }\end{array}$ & 5,3 & 4,8 & 3,9 & 6,8 & 3,8 & 2,5 \\
\hline $\begin{array}{l}\text { Mejoras aparcamiento en } \\
\text { Hayedo y Patones de Abajo }\end{array}$ & 5 & 7,5 & 3 & 5,4 & 4,6 & 8,7 \\
\hline Mesa del turismo & & & 7,9 & 8,4 & 6,8 & 5,7 \\
\hline Asociación de turismo & & & 5,8 & 7,5 & 7,4 & 6,7 \\
\hline $\begin{array}{l}\text { Potenciación de la oferta de } \\
\text { Patones de Abajo }\end{array}$ & & & & 7,9 & & 6,8 \\
\hline
\end{tabular}

Fuente: elaboración propia.

La valoración de las medidas por residentes y empresarios también muestra diferencias entre Montejo y Patones y respecto a las del resto de agentes. En Montejo la más valorada entre los residentes es la creación de Mesas de Turismo porque les permitiría participar en la gestión del fenómeno $(7,9)$, la creación del sistema de transporte colectivo $(6,9)$ y de una asociación de turismo $(5,8)$. Para los empresarios destaca por encima de cualquier otra la creación del sistema de transporte colectivo $(9,8)$, seguida de la creación de la asociación de turismo $(7,4)$ y la mesa de turismo $(6,8)$. En Patones los residentes valoran en primer lugar el sistema de trasporte colectivo $(8,5)$ seguido de la creación de la mesa de turismo $(8,4)$, la potenciación de la oferta en Patones de Abajo $(7,9)$, la creación de una Tasa para el turismo de Patones de Arriba $(7,6)$ y de la asociación de turismo $(7,5)$. Entre los empresarios de la localidad la medida más valorada es la ampliación del aparcamiento $(8,7)$, seguida a distancia por la potenciación de la oferta en Patones de Abajo $(6,8)$ y la creación de la asociación de turismo $(6,7)$. En cuanto a la creación de una mesa de turismo, experiencia que fue puesta en marcha y fracasó en buena medida por la incapacidad del colectivo, apenas es valorada con un 5,7 .

En definitiva, el análisis de la valoración de las acciones concluye que los mayores grados de satisfacción u aprobación se centran en una acción no ejecutada (sistema de transporte colectivo) y que esta es la única que recibe una alta puntuación entre todos los agentes, a excepción de los empresarios de Patones. En segundo lugar se sitúan, aunque con un mayor grado de discordancia entre agentes, dos relacionadas con la participación en la gestión del turismo: la creación de una Mesa de Turismo y de una Asociación sectorial. Por último, las medidas diseñadas específicamente para minimizar problemas de congestión del tráfico e 
incapacidad de estacionamiento (restricción/cuota diaria de vehículos y mejoras de los aparcamientos) reciben bajas valoraciones salvo entre visitantes y empresarios de Patones. En consecuencia se puede asumir el fracaso, al menos parcial, de las medidas que incorporan IP porque no han conseguido sensibilizar a los agentes acerca de los problemas que planteaban solucionar.

\section{V.4. Evaluación de las medidas que incorporan IP}

Aunque el enfoque teórico predominante en la aplicación de la IP es la conservación del patrimonio, el análisis de la calidad de los servicios y equipamientos y de su uso muestra una realidad bien distinta en los casos investigados. La evaluación de las medidas que incorporan IP revela claras diferencias entre Patones y Montejo que se extienden a su grado de aplicación y eficacia, cuestiones directamente relacionadas con los objetivos para las que fueron elaboradas (conservación, gestión de impactos o puesta en valor), su gestión y las capacidades e intereses de quienes las diseñan y aplican. En Montejo, la IP se ha utilizado preferentemente como instrumento para la conservación del patrimonio y la mayoría de servicios y equipamientos (Centro de Educación Ambiental del Hayedo de Montejo y servicios y equipamientos de la Reserva de la Biosfera de la Sierra del Rincón) son gestionados, mediante concesión administrativa de la CAM, por agentes no locales especializados. En Patones, por el contrario, el uso de la IP se focaliza en la puesta en valor del patrimonio y los servicios y equipamientos son gestionados por una administración local que no dispone de suficientes recursos humanos especializados en la materia.

Las mejores valoraciones de los servicios de Montejo que incorporan IP corresponden al servicio de visitas guiadas ofertado por técnicos especializados del CEA, en el interior del Hayedo. Su calidad es elevada incluyendo la gestión $(3,25$ sobre 4$)$, el mensaje $(3,25)$ y la aplicación de técnicas de interpretación $(3,4)$. Además, este es el servicio más utilizado por los residentes $(90 \%)$ y visitantes $(68 \%)$. La valoración de la visita guiada gestionada por la Reserva de la Biosfera es notoriamente inferior y aunque en términos turísticos puede calificarse como servicio atractivo $(2,8)$ que favorece el disfrute de quienes lo realizan, el tamaño del grupo es excesivo, el mensaje no cumple los estándares de calidad de interpretación $(1,75)$ y muestra carencias en la aplicación de técnicas interpretativas $(2,5)$. Por otra parte se trata de un servicio apenas utilizado por residentes (10\%) y visitantes $(16 \%)$. En cuanto a las rutas autoguiadas «Senda de la dehesilla» y «Senda del río Jarama y el Pinar», próximas al Hayedo y también gestionadas por el CEA, están bien diseñadas $(3$ y 3,2$)$ y presentan una relativamente adecuada gestión $(2,4$ y 2,8$)$ pero no cuentan con suficiente mantenimiento y apenas incorporan técnicas $(2$ y 2,3$)$ y contenidos interpretati$\operatorname{vos}(2,5$ y 2,5$)$. Además, apenas son utilizadas por visitantes $(6 \%$ y $2 \%)$ aunque quienes las utilizan aprovechan en buena medida los servicios ofrecidos (folleto, paneles y señales). Por último, el «Centro de Recursos de Montaña», gestionado por la empresa concesionaria de la gestión de la Reserva de la Biosfera, obtiene elevadas valoraciones en personal $(3,5)$, gestión $(3,2)$, diseño $(3,2)$ y atractivo de la exposición (3). Sin embargo, apenas incorpora técnicas de IP (2) y tampoco ofrece un mensaje que pueda considerarse interpretativo (2). En consecuencia, sus posibles impactos en cambios de valores que favorezcan la preservación del patrimonio y la articulación de modelos sostenibles de turismo han de ser 
limitados. En cualquier caso y a pesar de que ha perdido buena parte de su inicial carácter multifuncional, se trata del equipamiento más utilizado por residentes (90\%) y visitantes (76\%) de Montejo de la Sierra.

Varios proyectos en Patones, incluidos museos y centros de interpretación, elementos o conjuntos patrimoniales panelizados y rutas tematizadas, incorporan la IP, y en todos salvo uno se recurre a la disciplina para la puesta en valor del patrimonio. La excepción es el proyecto «Diseño de una guía interpretativa del patrimonio natural y cultural del municipio de Patones» y la publicación resultante «Un paseo por Patones: itinerarios didácticos para la Interpretación del Patrimonio». Como se ha señalado, ambos fueron concebidos considerando las potencialidades de la IP para la gestión sostenible del turismo y la conservación del legado natural y cultural pero apenas han sido aplicados. Entre los proyectos ejecutados que incorporan IP se evaluaron los emplazados en Patones de Arriba y su entorno inmediato: el centro de visitantes «CITECO», el «Ecomuseo de la Pizarra» y la «Senda Ecológica del Barranco de Patones». Todos son gestionados por el Ayuntamiento y se realizaron a partir de recomendaciones de propuestas de planificación del desarrollo turístico municipal.

La Senda Ecológica, acondicionada para ofrecer a los visitantes alternativas de acceso a Patones de Arriba y minimizar los impactos del tráfico y estacionamiento de vehículos, obtiene resultados muy inferiores a proyectos similares de Montejo: su gestión se valora como poco adecuada $(2,2)$, especialmente en mantenimiento y conservación, apenas puede considerarse un equipamiento interpretativo porque no utiliza técnicas apropiadas (2), el mensaje no se ajusta a los requisitos mínimos de la IP $(1,5)$ y pese a ser utilizado en alguna ocasión por la mayoría de los residentes $(81,8 \%)$ apenas es usado por los visitantes $(10,6 \%)$. El Ecomuseo de la Pizarra, iniciativa enfocada a la puesta en valor del patrimonio natural y cultural, no presenta buenos resultados en gestión $(2,2)$, diseño del recorrido $(2,2)$ y medio $(2,4)$. Tampoco puede ser considerado un servicio interpretativo porque no utiliza técnicas interpretativas $(1,7)$ y el mensaje $(2,3)$ apenas cumple los mínimos necesarios. Aunque es utilizado por el $63,8 \%$ de los visitantes buena parte de ellos reconocen no haberla recorrido en su totalidad y haber leído algunos paneles de forma aislada. Además, tampoco es un servicio utilizado por los residentes de la localidad (18,2\%). Por último, CITECO muestra elevados niveles de calidad en personal $(3,25)$, una gestión aceptable y un diseño del equipamiento adecuado $(2,8)$. Sin embargo tampoco puede considerarse un servicio de interpretación porque ni la exposición ni el audiovisual utilizan técnicas interpretativas (2) y el mensaje apenas cumple los requisitos (2). Este equipamiento, utilizado en alguna ocasión por la mayoría de los residentes (80\%), apenas es usado por el 23,4\% de los visitantes actuales constatándose un claro retroceso en este sentido respecto al $80 \%$ registrado en 2001 (Mercodes, 2003).

Los resultados obtenidos evidencian diferencias significativas en el uso y aplicación de técnicas de IP y permiten extraer una conclusión de carácter general: en la gran mayoría de los casos analizados no se cumplen los requisitos mínimos para que puedan ser considerados recursos interpretativos. Tan sólo en el Hayedo de Montejo se aplican con acierto las técnicas de la IP, cuestión que no sucede en otros recursos emplazados en el municipio como el Centro de Recursos de Montaña, las rutas autoguiadas y las rutas de la Reserva de la Biosfera. En cuanto a Patones, las carencias son comunes en todos los recursos evaluados: además de constatarse importantes disparidades en la valoración de técnicas de IP aplicadas, 
se registran múltiples carencias en contenidos de paneles, guías y folletos. Estos problemas pueden ser debidos a que han sido diseñados y son gestionados por técnicos que, pese a contar con amplios conocimientos sobre patrimonio natural, cultural y turismo, no disponen de la formación necesaria en IP. Los resultados también evidencian tres cuestiones relevantes en términos de sostenibilidad del turismo y uso de la IP: la primera es el uso generalizado de la IP como instrumento para la puesta en valor y/o trasmisión de información descriptiva sobre el patrimonio, un enfoque restrictivo que reduce sus potencialidades como herramienta para la planificación y gestión sostenible del turismo. La segunda es que los recursos mejor valorados son servicios que requieren la presencia física de técnicos especializados y la tercera que la mayoría de recursos muestran problemas de mantenimiento y conservación. Las dos últimas son aspectos centrales de la sostenibilidad del turismo en áreas rurales por su estrecha relación con la escasa capacidad financiera, técnica y de recursos humanos especializados de la mayoría de municipios. Así podemos entender que sean los servicios del Hayedo los mejor valorados: se trata de un espacio natural protegido cuyo funcionamiento es financiado con recursos de la CAM y que es gestionado desde hace años por personal con una muy elevada cualificación que incluye el conocimiento de las técnicas de la IP.

\section{CONCLUSIONES}

Los resultados de la investigación constatan un elevado grado de cumplimiento de las hipótesis de partida. En primer lugar se confirma que «La Interpretación del Patrimonio ha comenzado a utilizarse como herramienta de gestión turística en las áreas rurales españolas». Sin embargo, y a pesar del trabajo de difusión realizado desde entidades como la Asociación para la Interpretación del Patrimonio, suele utilizarse para la puesta en valor del patrimonio siendo escasas las experiencias que la utilizan como herramienta de gestión. En este sentido algunos autores consideran que detrás de los primeros impulsos europeos no existe una concepción de gestión y conservación como la estadounidense que permita el arranque y desarrollo de la IP (Santamarina, 2008). En cualquier caso podemos encontrar ejemplos de buenas prácticas en IP en Espacios Naturales Protegidos españoles como las señaladas en Sierra Nevada, Tablas de Daimiel, Islas Atlánticas o Burgos, donde se aplica con eficiencia. Estas cuestiones también se constatan en los estudios de caso centrados en la valoración del uso de la IP como herramienta de gestión en Patones y Montejo de la Sierra: sólo una minoría de servicios turísticos la utilizan para dirigir y controlar el flujo de visitantes, fomentar cambios de «valores sociales» y actitudes de respeto y conservación hacia el patrimonio, mientras que la mayoría utilizan el apelativo «interpretativo» sin cumplir los objetivos y principios necesarios para poder definirse como tales. Además, en los escasos ejemplos en los que la IP se utiliza como herramienta de gestión turística existe una relación directa entre el diseño y la prestación del servicio por parte de personal experto y cualificado específicamente en esta materia y la calidad, eficiencia y enfoque correcto de los servicios de IP. Una cuestión que requiere cierta capacidad financiera para soportan los gastos de este tipo de personal que, con frecuencia, no está al alcance de las administraciones locales rurales.

Respecto al grado de cumplimiento de la hipótesis «La Interpretación del Patrimonio es una eficiente herramienta de sostenibilidad turística en áreas rurales», conviene considerar tanto los aportes teóricos presentados como los resultados obtenidos en los estudios de caso. 
En la documentación revisada se identifican casos con resultados positivos como las experiencias «Expediciones Liblad» o «Fermata Inc», de la Universidad de Iohao, basada en un programa de capacitación en interpretación que desarrolló un modelo en el Parque Bentsen Río Grande para mostrar como la IP contribuye a reducir especies invasoras (Khol, 2009). A escala local y en el ámbito nacional, los estudios en Patones y Montejo han permitido identificar potencialidades y carencias en la aplicación de la IP en términos de sostenibilidad turística. En ambos casos la mayoría de los visitantes que consumen servicios de IP consideran que estos les ayudan a conocer el municipio y valorarlo más, dos objetivos de la disciplina. En Montejo estos servicios generan valor añadido a la experiencia turística, incrementan la satisfacción del visitante, contribuyen a diferenciar el destino, facilitan la puesta en valor del patrimonio y diversifican la oferta. Asimismo, la visita al Hayedo infunde actitudes de custodia y respeto y aumenta la conciencia de los usuarios sobre la necesidad de su conservación. En Patones, sin embargo, apenas se ha puesto en marcha servicios de IP de calidad por lo que difícilmente han contribuido a la sostenibilidad turística. En este caso, como sucede en otros ámbitos rurales españoles y también en Montejo, bajo el título de IP se ofertan servicios que, en su mayoría, tan solo aportan conocimientos e información sobre patrimonio. En este sentido también conviene tener presente que la IP tiene limitaciones por lo que debe complementarse con otras herramientas de sostenibilidad. Por ejemplo, los impactos del turismo en el Hayedo no se solucionaron exclusivamente con buenos servicios interpretativos y en Patones de Arriba son necesarias otras medidas para resolver los conflictos existentes, escenario donde cobran sentido los nuevos paradigmas de gestión del uso público que plantean la combinación de estrategias de gestión directa, otras relacionadas con la comunicación, como la IP (Muñoz y Benayas, 2008) y la planificación territorial del turismo.

En definitiva, a pesar de que la IP lleva años utilizándose en las áreas rurales españolas queda mucho por hacer para su adecuada aplicación como herramienta de sostenibilidad. Esta afirmación implica la necesidad de trascender enfoques centrados en su utilización exclusiva para la puesta en valor del patrimonio y orientar los esfuerzos en el aprovechamiento de sus potencialidades para la gestión de un turismo sostenible.

\section{BIBLIOGRAFÍA}

BENAYAS J., MUÑOZ M., GARCÍA D., TEJEDO P., DÍAZ M.J., ASENSIO M. y De ESTEBAN A. (2007): «Análisis de los modelos de uso público de la Red de Parques Nacionales». En Proyectos de investigación en Parques Nacionales: 2003/2006. O.A. Parques Nacionales, pp. 7-28.

BENAYAS, J., BLANCO, R. y GUTIÉRREZ, J. (2000): «Evaluación de la calidad de visitas guiadas a Espacios Naturales Protegidos». Tópicos de Educación Ambiental $\mathrm{n}^{\circ}$ 2, pp. 69-78.

CASTAÑO J.M. (2005): Psicología Social de los viajes y el turismo. International Thomson Editores.

CEBRIÁN, M.A. (2001): «Cuando los pájaros hablan: programa de Educación Infantil de la Senda de Fuentes Blancas». Boletín del Centro de Interpretación de la Naturaleza de Valladolid, n $^{\circ} 53$, pp. 11-13. 
EAGLES F.J., Mc COOL S. y HAYNES C. (2002): Turismo sostenible en áreas protegidas: Directrices de planificación y gestión. OMT, PNUMA, UICN.

EUROPARC ESPAÑA (2005): Manual sobre conceptos de Uso Público en Espacios Naturales Protegidos. Fundación Fernando González Bernáldez.

FULLANA P. y AYUSO S., 2002. Turismo Sostenible. Rubes Editorial.

GONZÁLEZ B. (1995): La Sierra del Rincón: reserva de naturaleza y arquitectura rural. Comunidad de Madrid.

HAM S. (2007): «¿Puede la interpretación marcar la diferencia? Respuesta a cuatro preguntas de psicología cognitiva y del comportamiento». Boletín de Interpretación $\mathrm{n}^{\circ} 17, \mathrm{pp}$. $10-16$.

HAM S. (1992): Interpretación Ambiental. Una guía práctica para gente con grandes ideas y presupuestos pequeños. Forest Wildlife and Range Experiment Station, Universidad de Idaho.

HUNTER C. y SHAW J. (2007): «The ecological footprint as a key indicator of sustainable tourisms». Tourism Management 28, pp. 465-57.

JACKSON J. y MURPHY P. (2006): «Cluster in regional tourism. An Astralian case». Annals of tourism research vol. 4, $\mathrm{n}^{\circ} 33$, pp. 1.018-1.035.

KHOL J. (2009): «Evitando los recortes presupuestarios. Sobrevivir a los recortes presupuestarios de interpretación del patrimonio significa adquirir relevancia». Boletín de Interpretación, $\mathrm{n}^{\mathrm{0}} 21$, pp. 24-27.

LIU A. y WALL G. (2006): «Planning tourism employment: a developing country perspective». Tourism Management $\mathrm{n}^{\circ} 27$, pp. 159-170.

MARTÍN F. y MARTÍN I. (2006): «Problemas de sostenibilidad turística en destinos rurales maduros: el ejemplo de Patones». En Destinos turísticos: viejos problemas, ¿nuevas soluciones?, Universidad de Castilla-La Mancha, 2008, pp. 503-514.

MERCODES (2003): Satisfacción de la clientela de Patones de Arriba. Ayuntamiento de Patones.

MONTESERÍN, O. (2006): «La Interpretación y puesta en valor del patrimonio: los Planes de Dinamización Turística». En Destinos turísticos: viejos problemas, ¿Nuevas soluciones? Ediciones de la Universidad de Castilla la Mancha, 2008, pp. 269-279.

MORALES J. GUERRA F. y SERANTES A. (2009): Base para la definición de competencias en interpretación del patrimonio - Fundamentos técnicos y metodológicos para definir las competencias profesionales de especialistas en interpretación del patrimonio en España. Seminario Permanente de IP del CENEAM.

MORALES, J. y HAM, S. (2008): «¿A qué interpretación nos referimos?». Boletín de Interpretación, $\mathrm{n}^{\circ} 19, \mathrm{pp} .4-7$.

MORALES J. (1998): Guía práctica para la interpretación del patrimonio: el arte de acercar el legado natural cultural al público visitante. Consejería de Cultura, Junta de Andalucía.

MUÑOZ M. y BENAYAS J. (2008): The educational - recreational use of protected areas as a means of sustainability. Enviromental Education.

MUÑOZ M. (2008): Evaluación y financiación del uso público en los Espacios Naturales Protegidos. El caso de la Red Española de Parques Nacionales. Tesis doctoral del Departamento de Ecología de la UAM. 
ORAMS M.B. (1996): «Using Interpretation to Mange Nature - base tourism». Journal of Sustainable Tourism, 4 (2), pp. 81-94.

ORTEGA J. (1998): «El patrimonio territorial: el territorio como recurso cultural y económico». Ciudades: Revista del Instituto de Urbanismo de la Universidad de Valladolid, $\mathrm{n}^{\circ}$ 4, pp. 33-48.

RUIZ J.P. y MORENO M. (2001): La Sierra del Rincón: Hombre y naturaleza a través del tiempo. Consejería de Medio Ambiente de la Comunidad de Madrid.

SANTAMARINA B. (2008): «De la educación a la interpretación patrimonial: patrimonio, interpretación y antropología». En Patrimonios culturales: educación e interpretación. Cruzando límites y produciendo alternativas, Congreso de Antropología, pp. 39-56.

SAXENA G. y ILBERY B. (2007): «Integrated rural tourism. A Border Case Study». Annals of Tourism Research, 35 (1), pp. 233-254.

SPANLE P., ALLEN D. y PUNEY (1974): Planificación de programas interpretativos. Organización de las Naciones Unidas para la Agricultura y la Alimentación.

TILDEN F. (1957): Interpreting Our Heritage. The University of North Carolina Press, Chapel Hill.

VILLA SAN ROQUE (2008): Datos de Ocupación de Alojamientos de la Sierra Norte, febrero de 2008. Patronato Madrileño de Áreas de Montaña.

WEARING S. y NEIL J. (1999): Ecoturismo: Impacto, Tendencias y Posibilidades, Síntesis. 
